\title{
Coca cola and pepsi cola impact burns repair and serum levels of endothelial growth factor and vascular endothelial growth factor receptor in rabbits.
}

\author{
Gong Zhuandi ${ }^{1}$, Lai Luju', Deng Yingying², Liang Haoqin², Wei Suocheng ${ }^{2 *}$ \\ ${ }^{1}$ Medicine College, Northwest University for Nationalities, Lanzhou, PR China \\ ${ }^{2}$ Life Science and Engineering College, Northwest University for Nationalities, Lanzhou, PR China
}

\begin{abstract}
Objective: The present study was designed to evaluate comparatively the effects of coca cola and pepsi cola on skin burns repair, serum levels of Endothelial Growth Factor (EGF) and Vascular Endothelial Growth Factor Receptor (VEGFR) in rabbits.

Methods: Thirty Japanese white rabbits were randomly assigned into three groups; coca cola-treated group, pepsi cola-treated group and control group $(n=10)$. Each rabbit was cauterized to make the second-degree skin cauterization burn (on d 0). Rabbits in coca cola-treated, pepsi cola-treated and control groups drank $20 \%$ coca cola, $20 \%$ pepsi cola and tap water, respectively. The tensile strength, blood glucose levels and serum levels EGF and VEGFR were determined.

Results: Burn repair periods of coca cola-treated group $(22.88 \pm 3.23 \mathrm{~d})$ and pepsi cola-treated group $(22.49 \pm 3.02 \mathrm{~d})$ were longer than that of control group $(20.25 \pm 3.11 \mathrm{~d})$. Tensile strengths of coca colatreated and pepsi cola-treated rabbits were decreased compared to control rabbits. Blood glucose levels of all rabbits were sharply increased following cauterization burns, and reached the peak value on $\mathrm{d} 3$, the increments in coco cola-treated, pepsi cola-treated and control groups were $36.32 \%, 37.50 \%$ and $\mathbf{2 9 . 4 7 \%}$, respectively. Serum EGF and VEGFR levels of coco cola-treated and pepsi cola-treated groups were slightly reduced after $\mathbf{d} 5$ in comparison with control group.

Conclusions: Ingestion of cola and pepsi cola could inhibit burn repair and physics strength of the healed tissues, also reduced serum EGF and VEGFR levels. Such, burned patients should limit or cease to drink carbonated beverages.
\end{abstract}

Keywords: Blood glucose, Endothelial growth factor, Vascular endothelial growth factor receptor, Tensile strength, Burns, Rabbits.

Accepted on September 24, 2017

\section{Introduction}

Recently carbonated beverages are the most popular drinks worldwide [1]. Drinking of carbonated beverages is one of the crucial harmful factors for peoples. It has been reported that the prevalence rates of obesity, type-II diabetes, the metabolic syndrome and malignant mammary tumors are raised along with increasing the consumption of carbonated beverages [2-4]. However, most studies concerning health damage impacts of carbonated beverages were questionnaire, or epidemiological retrospective or prospective investigations based on the native populations in a region [5-7]. Currently, little information exists about quantitative assessment of the effects of carbonated beverages intake on wound and burn healing, especially during therapy and care of burns $[8,9]$. Experimental studies are scanty $[10,11]$.

Skin burns can result in obvious changes in the burned areas and systemic reactions [12]. Severe burns lead to ultimately the pathological influences in the burn tissues. Inflammatory cells surrounding the microvasculature promote new angiogenesis through VEGF $[13,14]$. VEGF accelerates tissue repair by improving vascular permeability, and enhancing the proliferation of endothelial cells $[9,15]$. VEGF exert its actions by combining specific VEGF receptors expressed on endothelial cells to induce vasculogenesis [16]. However, it remains unknown what the quantitative correlations exist between skin burns repairs and levels of blood glucose, serum EGF and VEGFR as well as tensile strength $[3,13]$. Up to date, no researches have recorded whether ingestion of carbonated beverages impacts the repair process of skin burns during burn therapy.

The present study was conducted to assess comparatively the effects of coca cola and pepsi on burn healing, tensile strength and levels of blood glucose, EGF and VEGFR in rabbits, as well as to provide scientific bases for reasonably drinking carbonated beverages during therapy of the wound patients. 


\section{Materials and Methods}

\section{Animals and experimental design}

Thirty female Japanese white rabbits, 3 to 4 months old, were purchased from Experiment Animal Center, Lanzhou University (License No. SCXK (Gansu) 2005-0007) and prefed for one week. The animals were randomly allocated into three groups $(\mathrm{n}=10$, weighing $2.12 \pm 0.68 \mathrm{~kg})$ : coca colatreated group, pepsi cola-treated group and Control Group (CG). After the hairs were clipped and shaved, the dorsal chest was disinfected with $5 \%$ iodine tincture. Rabbits were anesthetized by intramuscularly injecting $0.2 \mathrm{mg} / \mathrm{kg}$ xylazine. $10 \mathrm{ml}$ of $0.5 \%$ procaine hydrochloride was subcutaneously injected into this region of every rabbit. Each rabbit was cauterized for $10 \mathrm{~s}$ with a broil-hot metal sheet of $3 \mathrm{~cm}$ diameter twice to make the second-degree cauterization burn and let the surface open (on d 0). Penicillin of $400000 \mathrm{IU}$ and $0.4 \mathrm{~g}$ streptomycin were strewn on the burn areas for $5 \mathrm{~d}$ to prevent infection. All rabbits were accurately weighed each day using an electronic balance, and raised in the rabbit cages equipped with automatic water dispensers in the experimental room. The room was maintained at $22-24^{\circ} \mathrm{C}$ and $30 \%$ to $50 \%$ relative humidity. All rabbits ingested allodially the commercial diet for rabbits (Lanzhou Taihua Feed Co. Ltd, China).

Coca cola and pepsi cola were purchased from the local supermarket in Lanzhou city, China. Preparation of 20\% coca cola (or pepsi cola) solution was made by diluting 1L pure coca cola (pepsi cola) with $4 \mathrm{~L}$ tap water. Rabbits in coca colatreated, pepsi cola-treated and control groups drank $20 \%$ coca cola, 20\% pepsi cola and tap water ad libitum, respectively. All procedures on animals' treatment and care were authorized by the Experiment Animal Care and Use Committee of Gansu province, China.

\section{Morphological observations and measurement of the injured areas}

The exudates and morphological alternations of burn surface were detected every day. The largest diameter of the burn location was daily detected using a vernier caliper until the finish of burns repairs. Burn repair period (days) was recorded for each rabbit.

\section{Determination of burn repair velocity}

The burn area for each rabbit was determined following the equation: area $=($ the square of maximum diameter $\times \pi) / 4\left(\mathrm{~cm}^{2}\right)$. Daily repair velocity was calculated, namely, daily repair velocity $=$ difference (initial area minus the actual area on the measurement day) $/ \mathrm{d}\left(\mathrm{cm}^{2} / \mathrm{d}\right)$.

\section{Blood samples collections}

After the burns making, blood sample was taken aseptically from each rabbit on days $0,3,5,7,14,21$ and 26 , respectively.
The samples were centrifuged (3000 g, $20 \mathrm{~min})$. The serum was collected, and stored at $-20^{\circ} \mathrm{C}$.

\section{Detections of glucose, EGF and VEGFR concentrations}

Blood glucose levels were determined utilizing glucometer (Arkray Inc. Japan). Serum levels of EGF and VEGFR were detected with Elisa kit of EGF and VEGFR for rabbits on the basis of the instruction manual (Shanghai Bangyi, Biological Technology Co. Ltd, Shanghai, China). The tests were executed in triplicate.

\section{Measurement of tensile strength}

After the burn healing of all rabbits was completed, the rabbit was anesthetized by injecting intramuscularly $0.2 \mathrm{mg} / \mathrm{kg}$ xylazine. $10 \mathrm{ml}$ of $0.5 \%$ procaine hydrochloride was subcutaneously injected into the healed burn location. A piece of full thickness skin of $1.5 \times 3 \mathrm{~cm}$ was harvested aseptically from this region. Skin specimen was mounted on the tension meter (Omega D670-44, CA, USA) and then stretched. Tensile strength was determined when the skin was ruptured [17].

\section{Statistical analysis}

Data are presented as means \pm standard errors. Statistical analysis was performed with SPSS version 18.0 (SPSS Inc., Chicago, IL, USA). After square root transformation of the data, all variables complied with the assumptions of one-way Analysis of Variance (ANOVA). Post-ANOVA comparisons between groups were carried out using the contrast option under the general linear model procedure (Scheffe test). Pvalues $<0.05$ were considered significant.

\section{Results}

\section{Morphological observations}

We evaluated macroscopic changes at the skin cauterization burn sites in coca cola-treated, pepsi cola-treated and control groups, respectively. The images were taken on days $0,3,7$, 10, 14 and 18. Burn sites exhibited a similar morphology in three groups on day 3 post-burn. In control group, the local skin was swelled on d 1. Massive serous fluid was exuded from the burn surface (Figure 1). Then the serous secretion decreased from d 3. The burn area became dry gradually. Germinal layer of epithelium regenerated obviously. Granulation tissues were formed on burned surfaces on d 10, and they covered the whole surface on $d$ 14. The scar was produced in burn location. Rabbits of coca cola-treated and pepsi cola-treated groups exhibited a delayed burn repair as compared with the control group.

\section{Daily repair velocities of burn areas}

As shown in Table 1, on d 0 the initial burn areas of the three groups were nearly the same sizes. Mean repair periods of coca cola-treated group $(22.48 \pm 3.23 \mathrm{~d})$ and pepsi cola-treated 
group $(22.89 \pm 3.02 \mathrm{~d})$ were longer than that of the control group $(20.25 \pm 3.11 \mathrm{~d})$. However, there was no significant statistical difference between groups. Maximum repair period was detected in pepsi cola-treated group. In comparison with control group $\left(0.369 \pm 0.241 \mathrm{~cm}^{2} / \mathrm{d}\right)$, burn repair velocities of coca cola-treated rabbits $\left(0.332 \pm 0.202 \mathrm{~cm}^{2} / \mathrm{d}\right)$ and pepsi colatreated rabbits $\left(0.339 \pm 0.193 \mathrm{~cm}^{2} / \mathrm{d}\right)$ were reduced, without significant difference between groups.

The findings indicated coca cola and pepsi cola could slightly lengthen burn repair duration in rabbits.
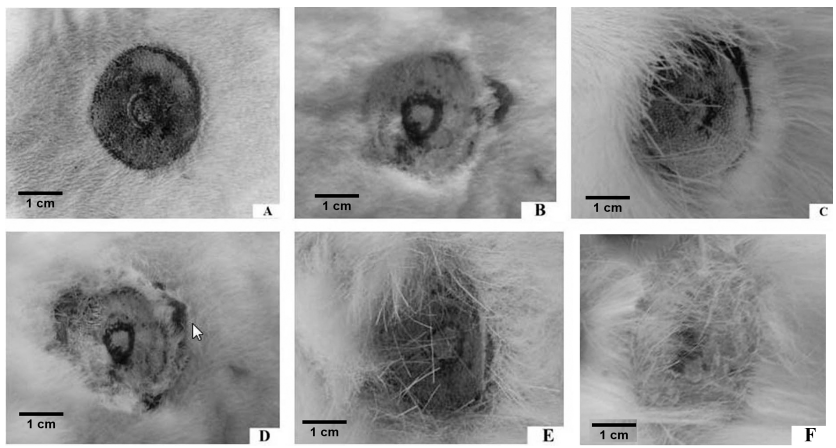

Figure 1. Local skin appearances of burn injuries (Bar=1cm). A-F represents local appearance of cauterized burn injury on d's 0, 3, 7, 10, 14 and 18 respectively. Numerous bright serous were exuded from the burn surface. Then the slurry secretion was decreased on day 3, and burn area became dry gradually. Germinal layer of epithelium regenerated obviously. The granulation tissue formed over burns on d 10 and covered the whole surface on d 14. Average time of clinical repairs in the control, coca cola-treated group and pepsi cola-treated rabbits were $20.25 \pm 3.11 d, 22.88 \pm 3.23 d$ and $22.49 \pm 3.02 d$, respectively.

\section{Tensile strengths}

Tensile strengths of coca cola-treated and pepsi cola-treated groups were less than that of control group. The reduction of $11.85 \%$ and $8.22 \%$ of tensile strengths were determined for coca cola-treated and pepsi cola-treated groups. The findings indicated that ingestion of $20 \%$ coca cola and pepsi cola could suppress the burn repair, reduce the physics strength of the healed burn tissues.

\section{Blood glucose levels in rabbits}

As compared to d 0 , blood glucose values of five groups were sharply increased on d's 3 and 7 (Figure 2). The blood glucose levels reached the peak, with the increments of $36.32 \%$, $37.50 \%$ and $29.47 \%$ in coca cola-treated, pepsi cola-treated and control groups, respectively. The results indicated that skin cauterization burns could lead to a rise in blood glucose levels in the rabbits. Coco-cola and pepsi-cola enhanced slightly blood glucose concentration.

\section{Serum EGF and VEGFR levels in four skin injuries}

Serum EGF levels: EGF levels of all rabbits decreased during the burn repair (Figure 3). On d 3, the values reached the bottom. EGF level in coca cola-treated group was significantly less than that of control group. The findings demonstrated the second-degree cauterization burns could reduce serum EGF level.

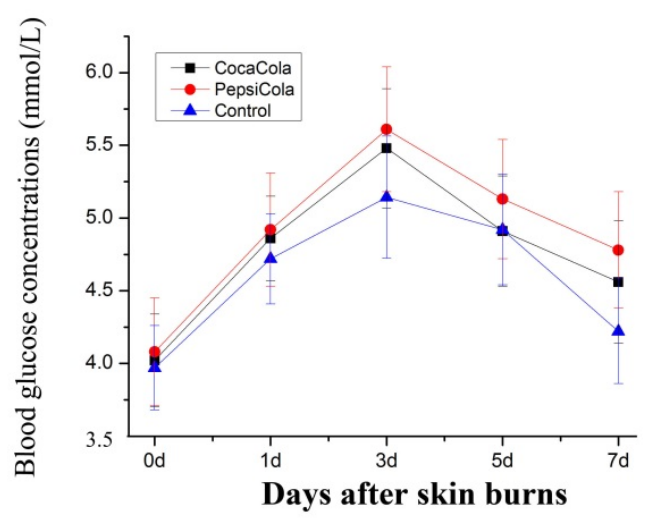

Figure 2. Blood glucose levels following skin cauterization burns. Notes: On the same day, the different superscript letters present that there was significant difference between groups $(P<0.05)$. The blood glucose levels were increased in comparison with day 0. On day 3, the levels reached to the peak, with the increments in coco-cola, pepsi-cola and control groups of 36.32\%, 37.50\% and 29.47\%, respectively. Increment in pepsi-cola rabbits was the maximum. Then the blood glucose levels decreased gradually. On d 7, blood glucose levels were still greater than that of $d 0$. The results indicated that skin cauterization burns could lead to an increase in blood glucose concentration of animals. Furthermore, drinking coco-cola and pepsi-cola enhanced blood glucose concentration.

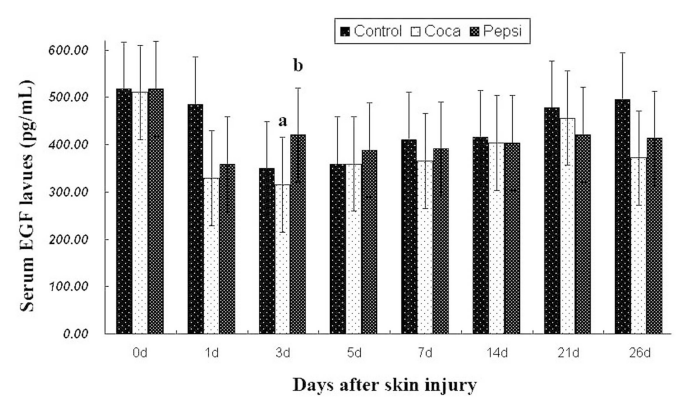

Figure 3. Serum EGF levels following skin cauterization burns. Note: The different low letters represent that there was significant difference between groups $(P<0.05)$.

Serum VEGFR levels: Serum VEGFR levels were reduced during the burn repair of rabbits, and reached the bottom on $\mathrm{d}$ 14, with a minimum in the coca cola-treated group as compared to control group. On d 26, serum VEGFR levels of coca cola-treated and pepsi cola-treated groups maintained lower levels than the control group. The results demonstrated that skin cauterization burns decreased serum VEGFR level (Figure 4).

Table 1. Repair time, repair velocity and tensile strength.

\begin{tabular}{lllll}
\hline Group & $\begin{array}{l}\text { Initial areas } \\
\left(\mathbf{c m}^{2}\right)\end{array}$ & $\begin{array}{l}\text { Repair } \\
\text { duration }(\mathbf{d})\end{array}$ & $\begin{array}{l}\text { Repair } \\
\text { velocity } \\
(\mathbf{c m} 2 / \mathbf{d})\end{array}$ & $\begin{array}{l}\text { Tensile } \\
\text { strength } \mathbf{( k g )}\end{array}$ \\
\hline Control group & $7.47 \pm 3.11$ & $20.25 \pm 3.11$ & $0.369 \pm 0.241$ & $3.29 \pm 1.34$ \\
\hline
\end{tabular}




\begin{tabular}{lcccc}
\hline $\begin{array}{l}\text { Coca } \\
\text { group }\end{array}$ & cola $7.46 \pm 3.50$ & $22.48 \pm 3.23$ & $0.332 \pm 0.202$ & $2.90 \pm 0.83$ \\
\hline $\begin{array}{l}\text { Pepsi } \\
\text { group }\end{array}$ & cola $7.53 \pm 3.83$ & $22.89 \pm 3.02$ & $0.339 \pm 0.193$ & $3.04 \pm 1.88$
\end{tabular}

Notes: Initial area indicated the skin injury area at $\mathrm{d} 0$.

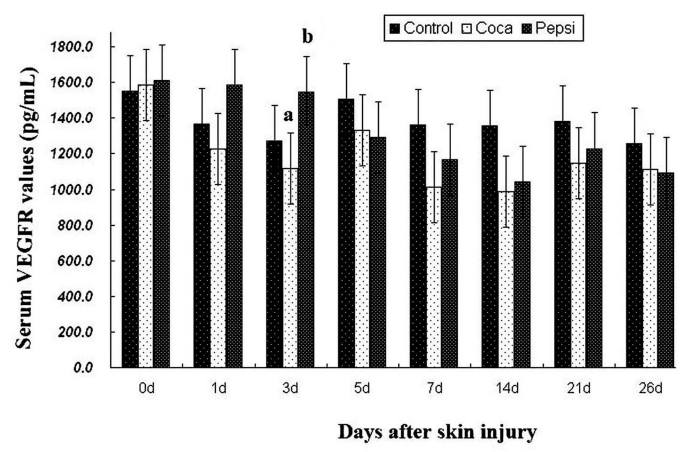

Figure 4. Serum VEGFR levels following skin cauterization burns. Note: The different low letters represent that there was significant difference between groups $(P<0.05)$.

\section{Discussions}

Blood glucose levels affected wound healing [18,19]. Researches on adults showed the post-trauma rising of blood glucose levels exhibited a positive correlation to the injury severity score [20]. In our study, the results indicated that skin cauterization burns could lead to an increase in blood glucose levels. Coca cola and pepsi cola enhanced obviously blood glucose levels. But, quantitative correlations between them remain unknown [14,21].

The vasculogenesis plays an important role in the skin maintenance and repair and relies on the participation and coordination of various cells [22]. Numerous factors influence angiogenesis and wound healing process [23]. Growth factors including EGF and VEGF are key modulators during wound healing. They are employed to wound therapy $[23,24]$. EGF and VEGF stimulate cellular migration, proliferation and angiogenesis. EGF enhances epidermal regeneration, cell motility and proliferation. VEGF is potent proangiogenic growth factors of the skin [25]. Sufficient VEGF levels promoted remarkably wound healing $[23,26]$. Currently, it is unspecified how VEGF contributes to skin wound healing by binding to VEGFR [25,27].

Previous study recorded there were no differences of VEGF and VEGFR levels between the control group and $10 \mathrm{mg} / \mathrm{kg}$ sildenafil group in severe scald burn in rats [28]. VEGF and VEGFR expression levels of partial-thickness scald rats were increased as compared to normal rats [29]. An investigation had indicated there was a remarkable expression of the EGF gene in burn wound, especially in the edge part of the burn surface [14]. Unfortunately, expression assay of $E G F$ gene was not performed in our study. Our study revealed that serum EGF levels of all rabbits were decreased after the second-degree skin cauterization burns were made. The least EGF level was detected in coca cola-treated group on d 3. Serum VEGFR levels were decreased during skin cauterization burn repair levels with a maximum reduction in coca cola-treated group on d 14 post skin burns. Our findings were consistent with early documents $[28,29]$.

Adequate tensile strength and biomechanical properties of the wounds depend upon the biochemical composition of the wound during the late remodeling stages of the wound healing [8]. The current study demonstrated that coca cola and pepsi cola during could reduce tensile strengths of the burned rabbits. The findings need to be thoroughly verified in additional animals.

\section{Conclusions}

Our data revealed that drinking coca cola and pepsi cola during burn healing could enhance blood glucose levels, inhibit wound contraction velocity and decrease physics strength of skin. Then they suppress the burn healing. Therefore the burned patients have to limit or cease to drink carbonated beverages so as to accelerate wound healing.

\section{Conflict of Interest}

None of the authors has any potential financial conflict of interest related to this manuscript.

\section{Authors Contributions}

Professor Gong Zhuandi detected the receptor gene expressions, and revised the manuscript critically for important intellectual content. Miss Lai Luju conducted the morphological observations. Miss Deng Yingying did the data statistics analyses. Miss Liang Haoqin did the ELISA assay and the data statistics analyses, and detected the morphological changes. Professor Wei Suocheng was responsible for the conception and design of the study experimental and writing the manuscript. All authors have approved the final version to be submitted.

\section{Acknowledgements}

The work received the support of the National Natural Science Foundation of The People's Republic of China (Grant No. 31460684), the Innovation Team Project for Animal Medical and Biological Engineering of Ministry of Education of China. The manuscript was checked using Ginger tools online.

\section{References}

1. Dhingra R, Sullivan L, Jacques PF, Wang TJ, Fox CS. Soft drink consumption and risk of developing cardiometabolic risk factors and the metabolic syndrome in middle-aged adults in the community. Circulation 2007; 116: 480-488.

2. Gibson S. Sugar-sweetened soft drinks and obesity: a systematic review of the evidence from observational studies and interventions. Nutr Res Rev 2008; 21: 134-147. 
3. Cuomo R, Andreozzi P, Zito FP. Alcoholic beverages and carbonated soft drinks: consumption and gastrointestinal cancer risks. Cancer Treat Res 2014; 159: 97-120.

4. Belpoggi F, Soffritti M, Tibaldi E, Falcioni L, Bua L, Trabucco F. Results of long-term carcinogenicity bioassays on coca-cola administered to Sprague-Dawley rats. Ann NY Acad Sci 2006; 1076: 736-752.

5. Malik VS, Schulze MB, Hu FB. Intake of sugar-sweetened beverages and weight gain: a systematic review. Am J Clin Nutr 2006; 84: 274-288.

6. Hatch EE, Wise LA, Mikkelsen EM, Christensen Tina R, Anders H, Sørensen, HT, Rothman KJ. Caffeinated beverage and soda consumption and time to pregnancy. Epidemiology 2012; 23: 393-401.

7. Rosario C, Paolo A, Francesco PZ. Alcoholic beverages and carbonated soft drinks: consumption and gastrointestinal cancer risks. Adv Nutr Cancer 2014; 159: 97-120.

8. Hozzein WN, Badr G, Al Ghamdi AA, Sayed A, Al-Waili NS, Garraud O. Topical application of propolis enhances cutaneous wound healing by promoting TGF-Beta/Smadmediated collagen production in a streptozotocin-induced type I diabetic mouse model. Cell Physiol Biochem 2015, 37: 940-954.

9. Badr G, Hozzein WN, Badr BM, Al Ghamdi A. Bee venom accelerates wound healing in diabetic mice by suppressing activating transcription factor-3 (ATF-3) and inducible nitric oxide synthase (iNOS)-mediated oxidative stress and recruiting bone marrow-derived endothelial progenitor cells. J Cell Physiol 2016; 231: 2159-2171.

10. Badr G. Camel whey protein enhances diabetic wound healing in a streptozotocin- induced diabetic mouse model: the critical role of beta-defensin-1, -2 and -3 . Lipids Health Dis 2013; 12: 1-11.

11. Banerjee P, Panda K, Nandi P, Banerjee SK. Oxidative damage of liver, kidney and serum proteins with apoptosis of above tissues in Guinea pigs fed on carbonated soft drink. Asian J Biochem 2013; 8: 1-13.

12. Emil R, Michael T. Wolf S. Skin injury model classification based on shape vector analysis. BMC Med Imag 2012; 12: $1-12$.

13. Gu T, Gu Y, Sui Z. The observation of EGF gene, EGFr gene and C-myc oncongene expression in the burns wound. Chin J Lab Diagn 2010; 14: 1431-1433.

14. Thanh D, Shawn B. Barry IR. Growth factors in wound healing: the present and the future? Clin Podiatr Med Surg 2015; 32: 109-119.

15. Frank S, Hubner G, Breier G, Longaker MT, Greenhalgh DG, Werner S. 1995. Regulation of vascular endothelial growth factor expression in cultured keratinocytes. Implications for normal and impaired wound healing. J Biol Chem 1995; 270: 12607-12613.

16. Carmeliet P. Mechanisms of angiogenesis and arteriogenesis. Nat Med 2000; 6: 389-395.
17. Wei S, Li Z. Pathological study on wound healing during Laser irradiation in sheep. China J Vet Med 1996; 22: 9-11.

18. Saikrishna Y, Gerard JF. Admission hyperglycemia as a prognostic indicator in trauma. J Trauma 2003; 55: 33-38.

19. Gamal B, Mohamed M, Ali M. Effects of under natured whey protein supplementation on CXCL12-and CCL21mediated $\mathrm{B}$ and $\mathrm{T}$ cell chemotaxis in diabetic mice. Lipids Health Dis 2011; 10: 203-211.

20. Isner JM, Asahara T. Angiogenesis and vasculogenesis as therapeutic strategies for postnatal neovascularization. J Clin Invest 1999; 103: 1231-1236.

21. Suliga E, Koziel D, Ciesla E, Gluszek S. Association between dietary patterns and metabolic syndrome in individuals with normal weight: a cross-sectional study. Nutr J 2015; 14: 1-10.

22. Ponugoti B, Xu F, Zhang C, Tian C, Pacios S, Graves DT. FOXO1 promotes wound healing through the up-regulation of TGF-b1 and prevention of oxidative stress. J Cell Biol 2013; 203: 327-343.

23. Bao P, Kodra A, Tomic-Canic M, Golinko MS, Ehrlich HP, Brem $H$. The role of vascular endothelial growth factor in wound healing. J Surg Res 2009; 153: 347-358.

24. Dogan S, Demirer S, Kepenekci I. Epidermal growth factor-containing wound closure enhances wound healing in nondiabetic and diabetic rats. Internat Wound J 2009; 6: 107-115.

25. Kelly EJ. Traci AW. Vascular endothelial growth factor and angiogenesis in the regulation of cutaneous wound repair. Adv Wound Care 2013; 3: 647-661.

26. Shibuya M. Vascular endothelial growth factor and its receptor system: physiological functions in angiogenesis and pathological roles in various diseases. J Biochem 2013; 153: 13-19.

27. Reinhard EFH, Carolin B, Markus G, Christian H. Vascular endothelial growth factor, basic fibroblast growth factor and epithelial growth factor receptor in peripheral nerve sheath tumors of neurofibromatosis type 1 . Anticancer Res 2015; 35: 137-144.

28. Ali K.G, Koksal D, Enver S. Alterations in serum vascular endothelial growth factor level in scald burn injury: an experimental study. Health Med 2013; 7: 1703-1708.

29. Liang Q. Abnormal regulation of neo-vascularisation in deep partial thickness scalds in rats with diabetes mellitus. Burns 2011; 37: 1015-1022.

\section{*Correspondence to}

Wei Suocheng

Life Science and Engineering College

Northwest University for Nationalities

PR China 